\title{
Cyclin-dependent kinase 4 and 6 inhibitors at the crossroads: the combinational therapeutic strategies in breast cancer-a narrative review
}

\author{
Yiqi Yang ${ }^{1 \#}$, Sha Zhu ${ }^{1,2 \#}$, Ziyi Fu ${ }^{1 \#}$, Chunxiao Sun ${ }^{1}$, Fan Yang ${ }^{1}$, Tianyu Zeng ${ }^{1}$, Yijia Hua ${ }^{1}$, Shengnan Bao ${ }^{1}$, \\ Xian Gao ${ }^{1}$, Xiang Huang ${ }^{1}$, Wei Li $^{1}$, Yongmei Yin ${ }^{1}$ \\ ${ }^{1}$ Department of Oncology, The First Affiliated Hospital with Nanjing Medical University, Nanjing, China; ${ }^{2}$ Department of Oncology, The Affiliated \\ Wuxi No.2 People's Hospital of Nanjing Medical University, Wuxi, China \\ Contributions: (I) Conception and design: Y Yang, Y Yin; (II) Administrative support: None; (III) Provision of study materials or patients: S Zhu, Z \\ Fu; (IV) Collection and assembly of data: T Zeng, Y Hua, S Bao, X Gao; (V) Data analysis and interpretation: C Sun, F Yang, X Huang, W Li; (VI) \\ Manuscript writing: All authors; (VII) Final approval of manuscript: All authors. \\ "These authors contributed equally to this work. \\ Correspondence to: Yongmei Yin. Department of Oncology, The First Affiliated Hospital with Nanjing Medical University, Nanjing 210029, China. \\ Email: ymyin@njmu.edu.cn.
}

\begin{abstract}
The successful development of cyclin-dependent kinase 4 and 6 (CDK4/6) inhibitors is of milestone significance. Since 2015, three CDK4/6 selective inhibitors (palbociclib, ribociclib, abemaciclib) have been developed by virtue of their outstanding performance in a series of studies, such as PALOMA, MONALEESA, and MONARCH. As CDK4/6 inhibitor monotherapy shows limited effectiveness, besides endocrine therapy (tamoxifen, AI, fulvestrant), an increasing number of laboratories and clinical researches exploring CDK4/6 inhibitor in combination with targeted therapy (HER2 targeted therapy, PI3K-mTOR/ AKT/FGFR/PARP inhibitors), chemotherapy, immunotherapy, and radiotherapy, have emerged and exhibited broad prospects in breast cancer treatment, indicating that the use of CDK4/6 inhibitors does not restrict to hormone receptor-positive and HER2-negative advanced breast cancers. This review summarizes and discusses the advances in combinational strategies of CDK4/6 inhibitors for the treatment of breast cancer to further expand its clinical efficacy, overcoming endocrine and even CDK4/6 inhibitors resistance. The combined therapies have achieved favorable clinical efficacy with tolerable adverse effects. However, more efforts are warranted to investigate the better combinations for individuals. The precise choice of target population, the extensive search of predictive biomarkers, and the deep exploration of resistance mechanisms might be the future directions, which will assist us in seeking more beneficial strategies of combined therapy for individuals to improve survival.
\end{abstract}

Keywords: Cyclin-dependent kinase 4 and 6 inhibitors (CDK4/6 inhibitors); breast cancer; combination therapy; endocrine resistance

Received: 23 November 2020; Accepted: 12 March 2021; Published: 30 April 2021.

doi: $10.21037 /$ tbcr-20-54

View this article at: http://dx.doi.org/10.21037/tbcr-20-54

\section{Introduction}

Breast cancer is the leading cause of cancer death among women, and hormone receptor-positive and human epidermal growth factor receptor 2-negative (HR+/HER2-) breast cancer is the most common subtype accounts for
$70 \%$ of all invasive breast cancer $(1,2)$. Endocrine therapy is the cornerstone of the treatment against hormone receptor-positive breast cancer, while endocrine resistance has been a critical clinical problem (3). The cyclindependent kinase 4 and 6 inhibitors (CDK4/6) have 
effectively improved the survival of advanced/metastatic HR+/HER2 - breast cancer patients with tolerable adverse effects, especially when combined with endocrine therapies, and could reverse the endocrine resistance to some extent (4). Palbociclib, ribociclib, and abemaciclib are the three selective CDK4/6 inhibitors approved by the US Food and Drug Administration (FDA) since 2015, which has changed the treatment pattern of hormone receptor-positive advanced breast cancer and has become the new standard of treatment. However, we are confronted with the problem of resistance to CDK4/6 inhibitors. In this review, we summarize the crucial advances in combined strategies of CDK4/6 inhibitor to provide ideas to this puzzle, exploring its maximized therapeutic effects to improve the survival further for breast cancer patients. We present the following article in accordance with the Narrative Review reporting checklist (available at http://dx.doi.org/10.21037/tbcr-20-54).

\section{Methods}

We searched the relevant studies published in English in the PubMed database from inception to Sep 30, 2020, using the search terms "breast cancer", "CDK4/6", "CDK 4/6", "cyclin-dependent kinases 4 and 6", and "palbociclib or ribociclib or abemaciclib". A total of 1,274 results were found. Articles in reference lists of key papers were also reviewed. Besides, pivotal oncology meetings were searched from Jan 1, 2017, to Sep 30, 2020.

\section{CDK4/6 inhibitors plus endocrine therapy}

Retinoblastoma protein (RB1) is a tumor suppressor, binding the E2F transcription factors to prevent G1 transition (5). CDK4 and CDK6 are considered pivotal regulatory factors in the cell cycle, complex with cyclin $\mathrm{D}$, phosphorylating RB1, deactivating RB1 function and releasing E2F successively, and then drive the cell cycle transiting from G1 phase to $\mathrm{S}$ phase (5). Meanwhile, E2F promotes the expression of cyclin $\mathrm{E}$, which binds to CDK2, and then hyper-phosphorylates Rb1, releasing E2F, and further facilitating the G1-S phase transition $(6,7)$ (Figure 1). However, this process is often dysregulated in cancer cells, which is one of the key properties of breast cancer cells, due to overexpression of cyclin $\mathrm{D} 1$ and loss of $\mathrm{Rb}(8,9)$. Mouse models lacking cyclin D1 and CDK4 prevent breast tumorigenesis $(10,11)$. Therefore, inhibitors of CDK4/6 halt the cell cycle at the G1 phase, preventing tumor progression.
Furthermore, cyclin D1 expression induced by estrogen activating CDK4/6 is characteristic in ER-positive breast cancer (12). Finn and colleagues find that luminal estrogen receptor-positive cell lines, as well as the ones with HER2 amplified, which usually have a functional RB1, are most sensitive to palbociclib (PD 0332991) (13). They also discover the synergistic effect of palbociclib and tamoxifen (13), which leads to multiple pivotal clinical trials verifying the therapeutic effects of CDK4/6 inhibitors plus endocrine therapy in hormone receptor-positive breast cancer.

\section{CDK4/6 inhibitors plus tamoxifen/aromatase inbibitors (AI)}

Palbociclib is the first selective CDK4/6 inhibitor that reveals the results of clinical studies. In phase III PALOMA-2 trial (14), for postmenopausal patients who are sensitive to endocrine therapy, the median progressionfree survival (PFS) of palbociclib plus letrozole group is significantly higher than that of the letrozole monotherapy group (24.8 vs. 14.5 months, $\mathrm{HR}=0.58, \mathrm{P}<0.001)$, which establishes the position of palbociclib combined with aromatase inhibitors (AIs) in the first-line treatment of hormone receptor-positive breast cancer. The favorable results are also seen in patients with visceral metastases (15). Subsequently, the MONALEESA-2 (16) and MONARCH 3 (17) trials report similar results as PALOMA-2, with the addition of ribociclib and abemaciclib to non-steroidal AIs (NSAI) respectively, which further consolidate the first-line treatment place of CDK4/6 inhibitor plus $\mathrm{AI}$ in advanced breast cancer.

Due to the difference in morbidity crowd, patients under the age of 50 account for $42 \%$ of breast cancer patients in the Asia-Pacific region (18), and is about $50 \%$ in the Middle East (19) and Latin American (20), while $20 \%$ in the USA (21), but there is limited data about the use of CDK4/6 inhibitors in previous studies in the premenopausal population. The MONALEESA-7 $(22,23)$ trial, for the first time, compares an NSAI or tamoxifen plus goserelin in combination with CDK4/6 inhibitor or placebo in premenopausal and perimenopausal patients with $\mathrm{HR}+$ / HER2 - advanced breast cancer. The result shows that the median PFS of the ribociclib combined with the endocrine therapy group reaches 23.8 months, which is much longer than 13.0 months in the placebo group, suggesting that ribociclib reduces the risk of disease progression by nearly half $(\mathrm{HR}=0.55, \mathrm{P}<0.001)(22)$. Compared with 


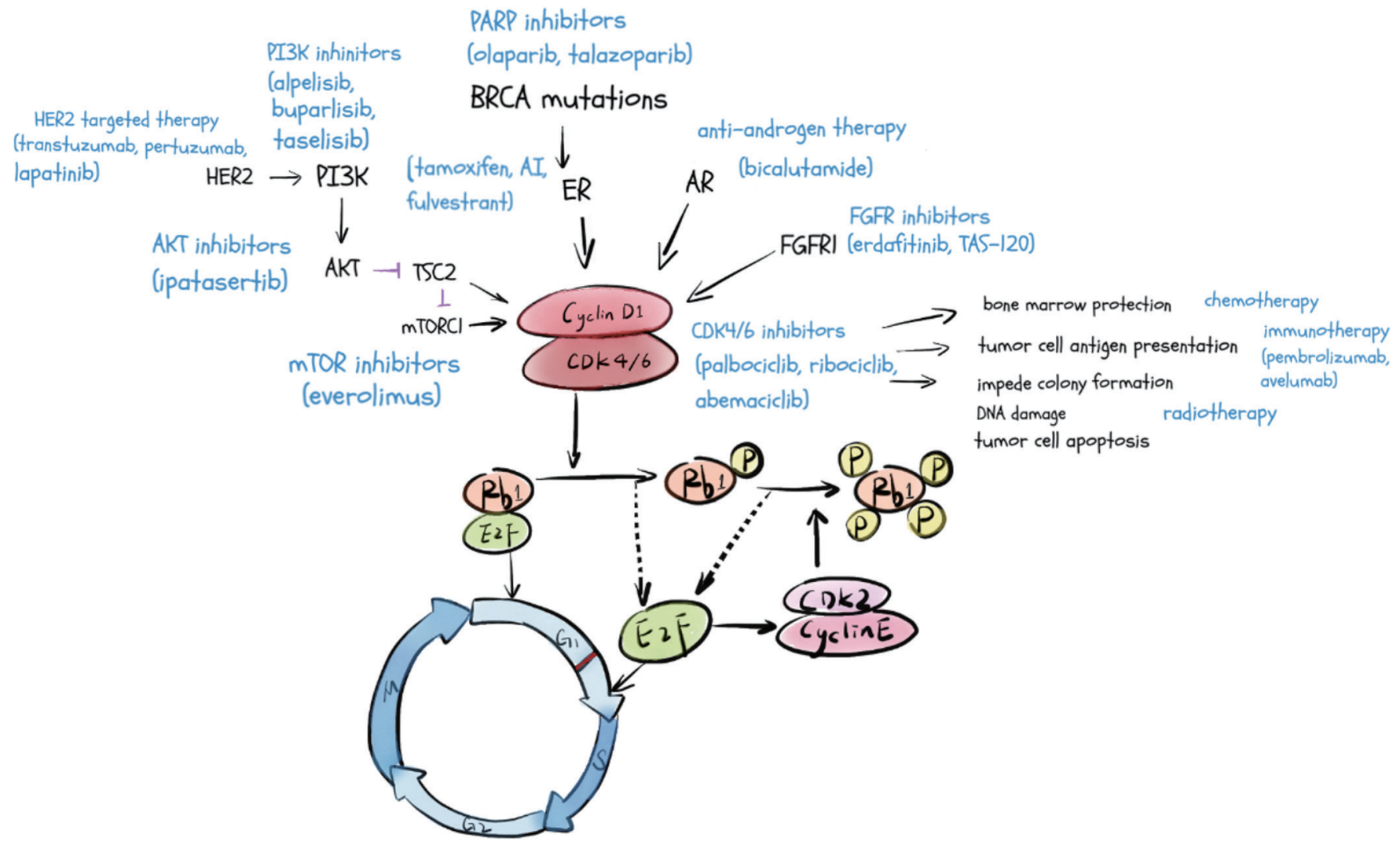

Figure 1 The cyclin D1-CDK4/6-Rb pathway and the combinational strategies of CDK4/6 inhibitors are indicated.

placebo, the addition of ribociclib significantly prolongs overall survival (not reached vs. 40.9 months, HR $=0.712$, $\mathrm{P}=0.00973$ ) as well (23). Therefore, the study confirms that for premenopausal or perimenopausal patients, ribociclib combined with AI or tamoxifen as first-line therapy has excellent effects after ovarian function suppression.

Which is better for HR+ advanced breast cancer, chemotherapy, or endocrine plus target therapy? The KCSG-BR 15-10 trial (NCT02592746) (24) compares the anti-tumor activity between capecitabine and endocrine therapy combination (exemestane, palbociclib, and GnRH agonist). The trial includes premenopausal HR+/HER2 - advanced breast cancer patients who have received tamoxifen or at most one line of chemotherapy for metastasis. Palbociclib, combined with exemestane and ovarian function suppression, prolongs PFS by 7.7 months compared to capecitabine (19.0 vs. 11.3 months, $\mathrm{HR}=0.659$, $\mathrm{P}=0.0469)$ (25). However, the subsequent PEARL study (NCT02028507) (26) shows that palbociclib plus endocrine therapy do not improve the PFS of postmenopausal patients with $\mathrm{AI}$ resistance compared to capecitabine (7.5 vs. 10.0 months, $\mathrm{HR}=1.09, \mathrm{P}=0.537)$, neither in the $\mathrm{ESR} 1$ wild-type sub-settings ( 8.0 vs. 10.6 months, $\mathrm{HR}=1.08$, $\mathrm{P}=0.526)$. These two studies compare CDK4/6 inhibitor plus endocrine therapy with capecitabine single-agent chemotherapy, but the results are inconsistent, probably attributed to the distinct enrolled population. The patients included in the KCSG-BR 15-10 trial are relatively sensitive to AI, while patients with endocrine-resistance breast cancer in the PEARL study account for the vast majority. It suggests that the combination of CDK4/6 inhibitor and endocrine therapy will achieve better efficacy in endocrinesensitive patients of early lines.

\section{CDK4/6 inbibitors plus fulvestrant}

The PALOMA-3 trial $(27,28)$ reports that the median PFS of the fulvestrant plus palbociclib treatment group is significantly improved compared with the fulvestrant group (9.5 vs. 4.6 months, $\mathrm{HR}=0.46, \mathrm{P}<0.0001$ ), and the median OS is extended by 6.9 months from 28.0 months (95\% CI, 23.6-34.6) in the control group to 34.9 months $(95 \% \mathrm{CI}$, 
28.8-40.0) in the treatment group yet with no statistical difference $(\mathrm{HR}=0.81, \mathrm{P}=0.09)$. In the MONARCH 2 trial $(29,30)$, the addition of abemaciclib significantly improves PFS and OS compared with fulvestrant alone: median PFS is 16.4 vs. 9.3 months ( $\mathrm{HR}=0.55, \mathrm{P}<0.001)$; median $\mathrm{OS}$ is 46.7 vs. 37.3 months ( $\mathrm{HR}=0.76, \mathrm{P}=0.01$ ). Given the premenopausal/perimenopausal subgroups, PALOMA-3 and MONARCH 2 trials both report significant improvements in PFS with the addition of CDK4/6 inhibitors to fulvestrant $(27,29)$.

MONALEESA-3 $(31,32)$ includes 726 postmenopausal HR+/HER2 - advanced breast cancer patients and the results indicate that ribociclib significantly improves the PFS (20.5 vs. 12.8 months, $\mathrm{HR}=0.59, \mathrm{P}<0.001$ ) and the OS as well (40.0 months $v s$. not reached, $\mathrm{HR}=0.72, \mathrm{P}=0.00455$ ). This study also demonstrates that CDK4/6 inhibitor combined with fulvestrant is effective for newly diagnosed (de novo) advanced breast cancer and patients relapse after completing adjuvant/neoadjuvant endocrine therapy for at least 12 months, which suggests that fulvestrant plus ribociclib becomes a favorable choice for first-line/secondline treatment of postmenopausal HR+/HER2- breast cancer $(31,32)$.

\section{Partner conundrum: AI or fulvestrant?}

Which is the better partner of CDK4/6 inhibitor, AI or fulvestrant? The PARSIFAL trial (33) (NCT02491983) answers this question, which compares the efficacy and safety of CDK4/6 inhibitors combined with fulvestrant or letrozole in endocrine-sensitive metastatic breast cancer patients of the first line. The trial reports no statistical difference in survival or incidence of severe adverse events between the fulvestrant and the letrozole groups (27.9 vs. 32.8 months, $\mathrm{HR}=1.1, \mathrm{P}=0.321$ ), and the non-inferiority hypothesis does not have a definitive conclusion (33). No difference is observed in pre-defined subgroups as well, such as with or without visceral involvement, newly diagnosed or metastatic breast cancer (33).

\section{CDK4/6 inhibitors plus anti-androgen therapy}

As regards androgen receptor (AR) expressing in onethird of triple-negative breast cancer (TNBC), antiandrogen enzalutamide has become a promising target therapy in AR-positive TNBC (34). Additionally, AR stimulates DNA replication through CDK activation and
$\mathrm{Rb}$ hyperphosphorylation in prostate cancer (35). The luminal AR (LAR) subgroup of TNBC is highly sensitive to CDK4/6 inhibitors compared to the basal-like subtype. The LAR subtype cells, which show sensitivity to palbociclib, exit mitosis into a quiescent state requiring CDK4/6 activity to reenter the cell cycle. In contrast, basal-like subtype cells exit mitosis bypassing the restriction point that requires CDK4/6 activity straight into a proliferative state (36). AR antagonist enhances the activity of palbociclib in ARpositive and RB proficient TNBC cells (37). Moreover, AR antagonist coupled with palbociclib re-sensitizes CDK4/6 inhibitor-resistant breast cancer cells (38). Clinical trials exploring the efficacy of this combination therapy are undergoing, such as a study exploring the efficacy of ribociclib with bicalutamide (NCT03090165) and palbociclib with bicalutamide (NCT02605486) in ARpositive TNBC.

\section{CDK4/6 inhibitors plus targeted therapy}

\section{CDK4/6 inhibitors plus HER2 targeted therapy}

HER2 amplified breast cancer cell lines representing the luminal subtype are also sensitive to CDK4/6 inhibitors, similar to ER+/HER2 - subtype (13). Preclinical studies indicate that CDK4/6 inhibitors target cyclin D1, which relates to the acquired resistance to HER2 inhibition, suppress Rb and TSC2 phosphorylation, attenuate mTORC1 activity, and thus augment the efficacy of HER2targeted therapies $(39,40)$. Such results are verified in clinical trials. The monarcHER trial (NCT02675231) includes breast cancer patients with previously at least 2 HER2-targeted therapies for advanced disease (41). The results reveal that abemaciclib in combination with fulvestrant and trastuzumab improves the PFS significantly compared to the group treated with chemotherapy and trastuzumab (8.3 vs. 5.7 months, $\mathrm{HR}=1.1, \mathrm{P}=0.051$ ) (41). Trastuzumab and pertuzumab plus palbociclib and fulvestrant are used as neoadjuvant therapy without chemotherapy in the NA-PHER2 study (42), which lead to a significant reduction of $\mathrm{Ki} 67$, and $27 \%$ of patients have a pathological complete response (pCR) in breast and axillary nodes, higher than pCR rate of $21 \%$ in TR006 trial (43) with the combination of lapatinib, trastuzumab, and letrozole. Various studies are ongoing, exploring the combinational therapeutic effects of CDK4/6 inhibitors and anti-HER2 therapy at different stages of breast cancer (Table 1). 
Table 1 Selected clinical trials exploring combination therapy of CDK4/6 inhibitors in breast cancer

\begin{tabular}{|c|c|c|c|c|c|c|}
\hline Study & $\begin{array}{l}\text { CDK4/6 } \\
\text { inhibitor }\end{array}$ & $\begin{array}{l}\text { Combination } \\
\text { therapy }\end{array}$ & Phase & $\begin{array}{l}\text { Sample size and } \\
\text { study population }\end{array}$ & $\begin{array}{l}\text { Primary } \\
\text { endpoint }\end{array}$ & Results \\
\hline \multicolumn{7}{|c|}{ CDK4/6 inhibitors plus tamoxifen/aromatase inhibitors } \\
\hline $\begin{array}{l}\text { PALOMA-2 } \\
\text { (NCT01740427) }\end{array}$ & Palbociclib & Letrozole & 3 & $\begin{array}{l}666, \text { postmenopausal } \\
\text { Al sensitive/treatment } \\
\text { naïve ER+/HER2- MBC }\end{array}$ & PFS & $\begin{array}{l}\text { Palbociclib + letrozole vs. } \\
\text { placebo + letrozole }(24.8 \\
\text { vs. } 14.5 \text { months, } H R=0.58 \text {, } \\
P<0.001)(14)\end{array}$ \\
\hline $\begin{array}{l}\text { MONALEESA-2 } \\
\text { (NCT01958021) }\end{array}$ & Ribociclib & Letrozole & 3 & $\begin{array}{l}668, \text { postmenopausal } \\
\text { Al sensitive/treatment } \\
\text { naïve ER+/HER2- MBC }\end{array}$ & PFS & $\begin{array}{l}\text { Ribociclib + letrozole vs. } \\
\text { placebo + letrozole }(25.3 \\
\text { vs. } 16.0 \text { months, HR =0.57, } \\
\mathrm{P}<0.001)(16)\end{array}$ \\
\hline $\begin{array}{l}\text { MONARCH plus } \\
\text { (NCT02763566) }\end{array}$ & Abemaciclib & $\begin{array}{l}\text { Anastrozole/ } \\
\text { letrozole }\end{array}$ & 3 & $\begin{array}{l}\text { 306, Al sensitive ER+/ } \\
\text { HER2- MBC }\end{array}$ & PFS & $\begin{array}{l}\text { Abemaciclib + NSAI vs. } \\
\text { placebo + NSAI (not reached } \\
\text { vs. } 14.73 \text { months, HR }=0.499 \text {, } \\
P=0.001 \text { ) (44) }\end{array}$ \\
\hline $\begin{array}{l}\text { MONALEESA-7 } \\
\text { (NCT02278120) }\end{array}$ & Ribociclib & $\mathrm{NSAl} /$ tamoxifen & 3 & $\begin{array}{l}\text { 672, premenopausal } \\
\text { ER+/HER2- MBC with } \\
\text { endocrine treatment } \\
\text { naïve for advanced } \\
\text { disease }\end{array}$ & PFS & $\begin{array}{l}\text { Ribociclib + NSAl/tamoxifen } \\
\text { vs. placebo + NSAl/tamoxifen } \\
(23.8 \text { vs. } 13.0 \text { months, HR } \\
=0.55, \mathrm{P}<0.001)(22)\end{array}$ \\
\hline $\begin{array}{l}\text { PELOPS } \\
\text { (NCT02764541) }\end{array}$ & Palbociclib & Tamoxifen & 2 & $\begin{array}{l}\text { 195, early-stage lobular } \\
\text { and ductal BC }\end{array}$ & Ki67, pCR & Not reported \\
\hline FELINE & Ribociclib & Letrozole & 2 & $\begin{array}{l}\text { 121, ER+/HER2- early- } \\
\text { stage BC }\end{array}$ & $\begin{array}{l}\text { Rate of PEPI } \\
\text { score } 0 \text { at surgery }\end{array}$ & Not reported \\
\hline $\begin{array}{l}\text { KCSG-BR 15-10 } \\
\text { (NCT02592746) }\end{array}$ & Palbociclib & Exemestane & 2 & $\begin{array}{l}\text { 182, ER+/HER2- } \\
\text { premenopausal MBC }\end{array}$ & PFS & $\begin{array}{l}\text { Palbociclib + exemestane } \\
\text { vs. capecitabine }(20.1 \text { vs. } \\
14.4 \text { months, } H R=0.659 \text {, } \\
P=0.0469)(24)\end{array}$ \\
\hline PARSIFAL & Palbociclib & $\begin{array}{l}\text { Fulvestrant/ } \\
\text { letrozole }\end{array}$ & 2 & $\begin{array}{l}\text { 486, Al sensitive ER+/ } \\
\text { HER2- MBC }\end{array}$ & PFS & $\begin{array}{l}\text { Palbociclib + fulvestrant vs. } \\
\text { palbociclib + letrozole groups } \\
(27.9 \text { vs. } 32.8 \text { months, HR } \\
=1.1, P=0.321)(33)\end{array}$ \\
\hline
\end{tabular}

Table 1 (continued) 
Table 1 (continued)

\begin{tabular}{|c|c|c|c|c|c|c|}
\hline Study & $\begin{array}{l}\text { CDK4/6 } \\
\text { inhibitor }\end{array}$ & $\begin{array}{l}\text { Combination } \\
\text { therapy }\end{array}$ & Phase & $\begin{array}{l}\text { Sample size and study } \\
\text { population }\end{array}$ & Primary endpoint & Results \\
\hline \multicolumn{7}{|c|}{ CDK4/6 inhibitors plus fulvestrant } \\
\hline $\begin{array}{l}\text { MONARCH } 2 \\
\text { (NCT02107703) }\end{array}$ & Abemaciclib & Fulvestrant & 3 & $\begin{array}{l}\text { 669, Al resistant, } \\
\text { chemotherapy naïve } \\
\text { ER+/HER2- MBC }\end{array}$ & PFS & $\begin{array}{l}\text { Abemaciclib + fulvestrant vs. } \\
\text { placebo + fulvestrant }(16.4 \\
\text { vs. } 9.3 \text { months HR }=0.55 \\
\mathrm{P}<0.001)(29)\end{array}$ \\
\hline $\begin{array}{l}\text { PEARL } \\
\text { (NCT02028507) }\end{array}$ & Palbociclib & Fulvestrant & 3 & 601, ER+/HER2- MBC & PFS & $\begin{array}{l}\text { Palbociclib + fulvestrant } \\
\text { vs. capecitabine }(7.5 \text { vs. } \\
10.0 \text { months, } H R=1.09 \text {, } \\
P=0.537)(26)\end{array}$ \\
\hline $\begin{array}{l}\text { MAINTAIN } \\
\text { (NCT02632045) }\end{array}$ & Ribociclib & Fulvestrant & 2 & $\begin{array}{l}\text { 132, ER+/HER2- MBC } \\
\text { with progression on } \mathrm{Al}+ \\
\text { palbociclib/ribociclib }\end{array}$ & $\begin{array}{l}\text { Percent of } \\
\text { progression-free } \\
\text { at } 24 \text { weeks }\end{array}$ & Not reported \\
\hline \multicolumn{7}{|c|}{ CDK4/6 inhibitors plus anti-androgen therapy } \\
\hline NCT03090165 & Ribociclib & Bicalutamide & $1 / 2$ & $11, A R+M B C$ & MTD, CBR & Not reported \\
\hline NCT02605486 & Palbociclib & Bicalutamide & $1 / 2$ & $51, A R+M B C$ & Dose, PFS & Not reported \\
\hline \multicolumn{7}{|c|}{ CDK4/6 inhibitors plus HER2 targeted therapy } \\
\hline $\begin{array}{l}\text { NA-PHER2 } \\
\text { (NCT02530424) }\end{array}$ & Palbociclib & $\begin{array}{l}\text { Trastuzumab + } \\
\text { pertuzumab + } \\
\text { fulvestrant }\end{array}$ & 2 & $\begin{array}{l}36 \text {, early invasive } B C \\
\text { with } \mathrm{HR}+/ \mathrm{HER} 2+\text { not } \\
\text { previously treated }\end{array}$ & Ki67, pCR & $\begin{array}{l}\text { The expression of } \mathrm{Ki} 67 \text { is } \\
\text { significantly reduced ( } 42 \text { ) }\end{array}$ \\
\hline $\begin{array}{l}\text { MonarcHER } \\
\text { (NCT02675231) }\end{array}$ & Abemaciclib & $\begin{array}{l}\text { Trastuzumab + } \\
\text { fulvestrant }\end{array}$ & 2 & $\begin{array}{l}237, \text { ER+/HER2- locally } \\
\text { advanced or metastatic } \\
\text { BC with } \geq 2 \text { HER2- } \\
\text { targeted therapies for } \\
\text { advanced disease }\end{array}$ & PFS & $\begin{array}{l}\text { Abemaciclib + fulvestrant + } \\
\text { trastuzumab vs. standard- } \\
\text { of-care chemotherapy + } \\
\text { trastuzumab ( } 8.3 \text { vs. } \\
5.7 \text { months, HR }=1.1 \\
P=0.051)(41)\end{array}$ \\
\hline
\end{tabular}

Table 1 (continued) 
Table 1 (continued)

\begin{tabular}{|c|c|c|c|c|c|c|}
\hline Study & $\begin{array}{l}\text { CDK4/6 } \\
\text { inhibitor }\end{array}$ & $\begin{array}{l}\text { Combination } \\
\text { therapy }\end{array}$ & Phase & $\begin{array}{l}\text { Sample size and study } \\
\text { population }\end{array}$ & Primary endpoint & Results \\
\hline $\begin{array}{l}\text { TOUCH } \\
\text { (NCT03644186) }\end{array}$ & Palbociclib & $\begin{array}{l}\text { Trastuzumab + } \\
\text { pertuzumab + } \\
\text { letrozole }\end{array}$ & 2 & $\begin{array}{l}\text { 144, ER+/HER2+ } \\
\text { early BC }\end{array}$ & $\mathrm{pCR}$ & Not reported \\
\hline $\begin{array}{l}\text { PATRICIA } \\
\text { (NCT02448420) }\end{array}$ & Palbociclib & $\begin{array}{l}\text { Trastuzumab } \pm \\
\text { letrozole }\end{array}$ & 2 & $\begin{array}{l}232, \mathrm{ER} \pm / \mathrm{HER} 2+ \\
\text { locally advanced or } \\
\text { metastatic BC }\end{array}$ & PFS & Not reported \\
\hline $\begin{array}{l}\text { PATINA } \\
\text { (NCT02947685) }\end{array}$ & Palbociclib & $\begin{array}{l}\text { Anti-HER2 } \\
+ \text { endocrine } \\
\text { therapy }\end{array}$ & 3 & $\begin{array}{l}\text { ER+/HER2+ MBC with } \\
\text { previous CT containing } \\
\text { anti-HER2 based } \\
\text { induction therapy }\end{array}$ & PFS & Not reported \\
\hline NCT02088684 & Ribociclib & $\begin{array}{l}\text { Buparlisib/ } \\
\text { alpelisib + } \\
\text { fulvestrant }\end{array}$ & $1 / 2$ & $\begin{array}{l}70, \mathrm{HR}+/ \mathrm{HER} 2+ \\
\text { locally recurrent or } \\
\text { advanced MBC }\end{array}$ & DLT, PFS & Not reported \\
\hline NCT03128619 & Palbociclib & $\begin{array}{l}\text { Copanlisib + } \\
\text { letrozole }\end{array}$ & $1 / 2$ & 102, HR+/HER2- BC & Ki-67, DLT & Not reported \\
\hline \multicolumn{7}{|c|}{ CDK4/6 inhibitors plus AKT inhibitors } \\
\hline \multicolumn{7}{|c|}{ CDK4/6 inhibitors plus PARP inhibitors } \\
\hline NCT03685331 & Palbociclib & $\begin{array}{l}\text { Olaparib + } \\
\text { fulvestrant }\end{array}$ & $1 / 2$ & $\begin{array}{l}\text { 54, BRCA-mutated } \\
\text { HR+/HER2- MBC }\end{array}$ & PFS & Not reported \\
\hline \multicolumn{7}{|c|}{ CDK4/6 inhibitors plus chemotherapy } \\
\hline NCT02978716 & Trilaciclib & $\begin{array}{l}\text { Gemcitabine } \\
\text { and carboplatin }\end{array}$ & 2 & 102, metastatic TNBC & TRAE & $\begin{array}{l}\text { Trilaciclib + gemcitabine + } \\
\text { carboplatin vs. gemcitabine } \\
\text { + carboplatin (No } \\
\text { significant differences in } \\
\text { myelosuppression } \\
\text { endpoints) (49) }\end{array}$ \\
\hline
\end{tabular}

Table 1 (continued) 
Table 1 (continued)

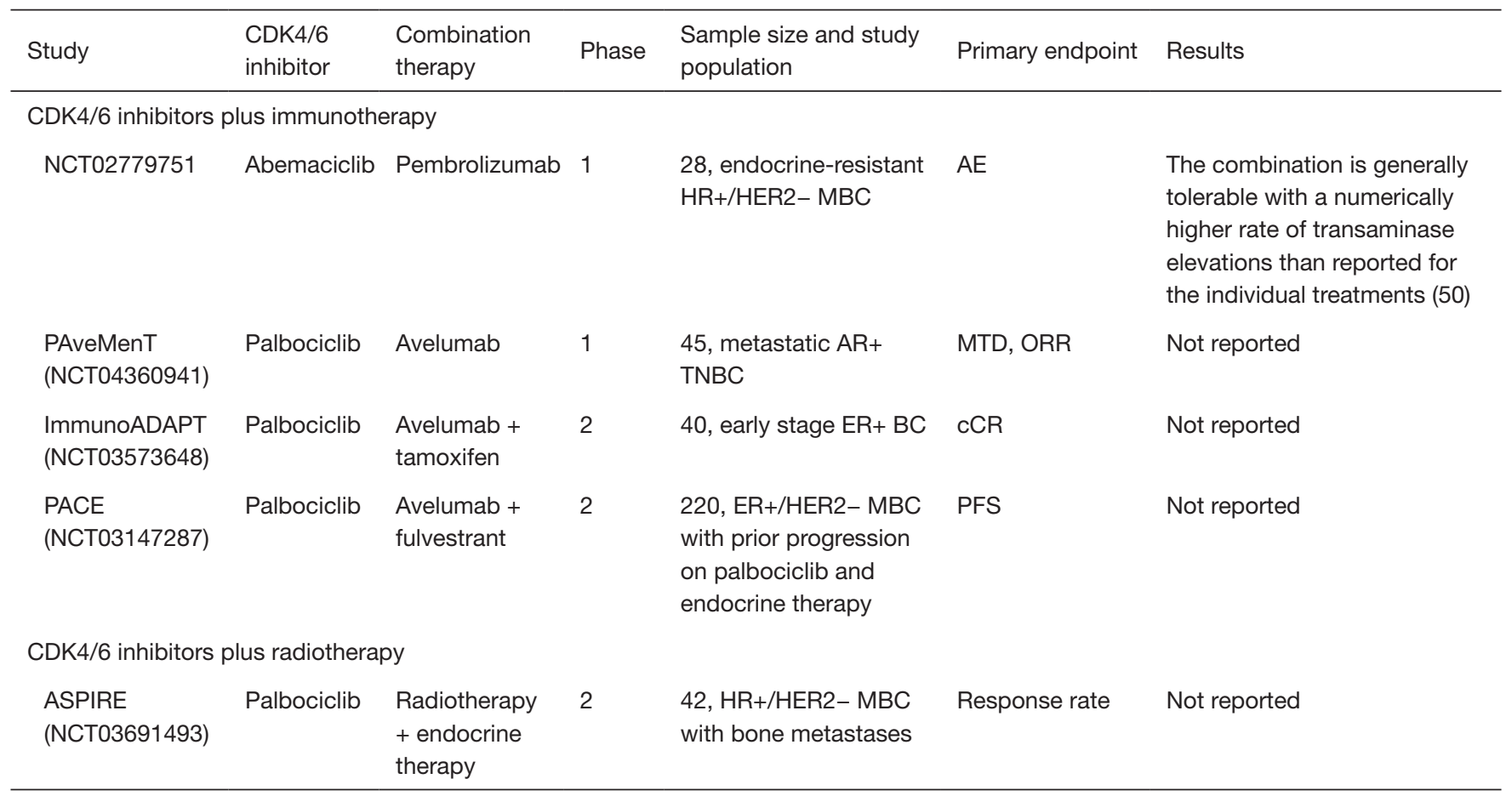

BC, breast cancer; MBC, metastatic breast cancer; HR+, hormone receptor-positive; HER2, humane epidermal receptor 2; TNBC, triple-negative breast cancer; AR+, androgen receptor-positive; Al, aromatase inhibitor; NSAI, non-steroidal aromatase inhibitor; CT, chemotherapy; PFS, progression-free survival; pCR, pathological complete response; cCR, clinical complete response; RBC, residual cancer burden; PEPI, pre-operative endocrine prognostic index; ORR, objective response rate; MTD, maximum tolerated dose; CBR, clinical benefit rate; DLTs, dose-limiting toxicities; AE, adverse events; TEAE, treatment-emergent adverse events; TRAE, treatment-related adverse event.

\section{CDK4/6 inbibitors plus PI3K-mTOR inbibitors}

Thirty percent of ER+/HER2- metastatic breast cancers have activating PIK3CA mutations (51). In vivo and in vitro studies evince that CDK4/6 inhibitors synergize with PI3K inhibition by partially attenuating mTORC1 activity (40), sensitizing PIK3CA-mutated cells (52), and triggering cancer cell apoptosis (53). These findings lead to a multicenter, open-label phase Ib/II study (NCT02088684) (54) investigating LEE011 (ribociclib), BKM120 (buparlisib, PI3K-pan class I-inhibitor) or BYL719 (alpelisib, PI3Kalpha specific class I inhibitor) in combination with fulvestrant, with the results not opened yet. Furthermore, Herrera-Abreu indicates that a combination of endocrine therapy, CDK4/6, and PI3K inhibition is more effective than the combination without endocrine therapy in a PDX model (53). This synergistic effect is also recognized in PIK3CA-mutant TNBC cell lines and TNBC tumors in vivo $(36,55)$. We look forward to the results of the joint effect.

\section{CDK4/6 inbibitors plus AKT inbibitors}

A proportion of $1.4-8 \%$ of breast cancer patients have AKT1 mutations, restricted to hormone receptorpositive breast cancers $(56,57)$. However, AKT activation is associated with a worse clinical outcome and induces endocrine resistance among patients treated with endocrine therapy $(58,59)$. Preclinical studies suggest that AKT1 activation can drive resistance to CDK4/6 inhibitors (60). The phase Ib trial TAKTIC (NCT03959891) (48) exploring the anti-tumor activity of palbociclib in combination with fulvestrant and ipatasertib, an AKT1 inhibitor, following CDK4/6 inhibitors progression demonstrates clinical benefit. The combination is well tolerated and does not affect the pharmacokinetics of ipatasertib (48).

\section{CDK4/6 inbibitors plus FGFR inbibitors}

Formisano and colleagues $(61,62)$ identify FGFR1 signaling as a potential mechanism of resistance to CDK4/6 inhibitors 
in combination with endocrine therapy in preclinical studies, while the resistance can be blocked by lucitanib, the FGFR tyrosine kinase inhibitor (61); 41\% (14/34) specimens progressing on CDK4/6 inhibitors are identified FGFR1/2 amplification or activating mutations. Patients in MONALEESA-2 with higher FGFR1 mRNA expression levels exhibit a significantly shorter PFS compared to patients with lower levels (61). Recent studies are worth waiting that exploring the treatment of FGFR-amplified/ hormone receptor-positive metastatic breast cancer with erdafitinib plus fulvestrant plus palbociclib (NCT03238196) and an oral FGFR inhibitor, TAS-120, from FOENIXMBC2 trial (NCT04024436).

\section{CDK4/6 inbibitors plus PARP inbibitors}

ER-positive breast cancers account for $22 \%$ and $77 \%$ of breast cancer patients with BRCA1 and BRCA2 mutations, respectively (63). ER-positive breast cancers with BRCA mutations are often characterized by more aggressive tumor statues, which result in a higher risk of distance recurrence and death $(64,65)$. Studies investigating the relationship between BRCA1 and ER $\alpha$ suggest that BRCA1 mutation releases the brake on $\mathrm{ER} \alpha$-driven proliferation, which is functioned by wild-type BRCA1 gene $(66,67)$. BRCA1 knockdown also promotes aromatase expression and thus may cause an elevated estrogen level (68). In addition, BRCA1 mutation abolishes the antiproliferative property of BRCA1 which binds to phosphorylated $\mathrm{Rb}$ and is involved in cell cycle arrest (69). Moreover, cyclin D1 that activates CDK4 and CDK6 plays a kinase-independent role in DNA repair, and the recruitment of cyclin D1 to DNA damage sites is through BRCA2 (70). Furthermore, CDK4/6 inhibition increases error-prone DNA repair, which suggests the synthetic lethal effect in BRCA mutated breast cancer $(71,72)$.

Poly(adenosine diphosphate-ribose) polymerase (PARP) inhibitor prevents the participation of PARP1 and PARP2 in DNA repair, which indicates the potential clinical use in germline BRCA mutated breast cancer based on the rationale of synthetic lethality $(73,74)$. The phase III OlympiAD and EMBRACE trials report significant PFS improvement in PARP inhibitor olaparib and talazoparib groups over standard-therapy groups in HER2-negative metastatic breast cancer patients with germline BRCA mutation $(75,76)$. The study has recently started exploring olaparib, palbociclib, and fulvestrant in patients BRCAmutated hormone receptor-positive, HER2-negative metastatic breast cancer (NCT03685331).

\section{CDK4/6 inhibitors plus chemotherapy}

Cell cycle arrest induced by CDK4/6 inhibitors antagonizes cytotoxic therapeutic strategies and result in reduced antitumor efficacy when combined with DNA-damaging chemotherapy, such as carboplatin and doxorubicin $(71,77)$. On the other hand, CDK4/6 inhibitors show bone marrow protection on chemotherapy- or ionizing radiation-induced myelosuppression in vitro even in CDK4/6-resistant tumors without dose reduction $(77,78)$, so as not to compromise distant survival (79). A phase II randomized clinical trial (NCT02978716) finds that the addition of trilaciclib to gemcitabine and carboplatin makes fewer patients have anemia who need red blood cell transfusions and improves the overall survival markedly (17.8 vs. 12.6 months, $\mathrm{P}=0.0023)(49)$.

\section{CDK4/6 inhibitors plus immunotherapy}

Selective CDK4/6 inhibitors not only induce G0 and G1 cell-cycle arrest but also enhance tumor cell antigen presentation as well as suppress regulatory $\mathrm{T}$ cell proliferation, which reduce the transcription of DNA methyltransferase 1, the target of E2F. In general, these factors lead to the enhanced clearance of tumor cells mediated by cytotoxic $\mathrm{T}$ cells with the combined therapy of CDK 4/6 inhibitors and immunotherapy (80). Also, CDK 4/6 inhibitors increase the infiltration of tumor cells and activate effector $\mathrm{T}$ cells via de-repression of the nuclear factor of activated T cell (NFAT) proteins, which synergize with immunotherapies (81). Moreover, CDK4/6 inhibitors hinder the phosphorylation of speckle-type POZ protein (SPOP), promote its degradation, and increase the PD-L1 protein levels (82). By combining a CDK4/6 inhibitor with immunotherapy, tumor regresses, and overall survival rates improve significantly in vivo (82). Additional immune checkpoint inhibitor combined with PI3Kalpha and CDK4/6 inhibition induces consistent tumor regression in the TNBC mouse model by enhancing tumor immunogenicity and T-cell cytotoxicity responses (55). The combination of abemaciclib and pembrolizumab shows numerically higher but not significantly better outcomes in $28 \mathrm{HR}+/ \mathrm{HER} 2$ - metastatic breast cancer patients from a phase Ib study (NCT02779751) (50), compared to previous data of abemaciclib monotherapy. More ongoing studies validating the efficacy of combination therapies with 
immunotherapy have the potential to fortify the clinical benefits of combined treatment.

\section{CDK4/6 inhibitors plus other agents}

\section{CDK4/6 inbibitors plus lysosome-destabilizing compounds}

CDK4/6 inhibitors are found to be absorbed into tumor cell lysosomes, which brings about the resistance of a subgroup TNBC to CDK4/6 inhibitors. Fassl and colleagues (83) develop new CDK4/6 inhibitor compounds evading the sequestration of lysosomal and reversing the drug resistance in TNBC cells.

\section{CDK4/6 inhibitors plus radiotherapy}

Brain metastases are common during the extending lifespan of breast cancer patients and are usually treated with surgery, radiotherapy, and systemic therapy (84-86). Preclinical studies indicate that abemaciclib penetrates the blood-brain barrier (87). A phase II clinical trial shows the anti-tumor activity of abemaciclib in hormone receptorpositive breast cancer patients with brain metastases (88). The combined use of palbociclib and radiotherapy impedes colony formation, inhibits DNA damage repair, and promotes tumor cell apoptosis synergistically in glioblastoma cell lines $(89,90)$. A retrospective study analyzes patients who receive stereotactic radiotherapy to brain metastases alongside palbociclib/abemaciclib (91). Fifteen patients with 42 metastatic brain lesions are included (91). The radiotherapy is well-tolerated in combination with CDK4/6 inhibitors, two lesions developing radionecrosis managed with steroids and bevacizumab (91). Six- and 12 -month local brain control is both $88 \%$, and distant brain control is $61 \%$ and $39 \%$ respectively, similar to the previous data (91). However, there is an improvement in overall survival (36.7 months) from the date of brain metastases diagnosis (91). Besides, the phase II ASPIRE trial (NCT03691493) is evaluating the response rate of concurrent palbociclib and radiotherapy for hormone receptor-positive patients with bone metastasis.

\section{Conclusions}

Over the past decades, CDK4/6 inhibitors have altered the therapeutic landscape, and endocrine therapy combined with CDK4/6 inhibitors become the standard first-line treatment against hormone receptor-positive breast cancer.
The potential synergistic effect of CDK4/6 inhibitors with other medical treatments has drawn more attention (Figure 1), at the crossroads of endocrine therapy and CDK4/6 inhibitor resistance. Plenty of ongoing clinical studies investigating the combinational strategies of CDK4/6 inhibitors has set off (Table 1) and promised an encompassing clinical profit to breast cancer patients. However, to enhance the efficacy of combination treatment, well-designed research and concrete answers about signaling mechanisms are urgently needed and require more scientific effort. Exploratory research in the predictive biomarkers and resistance mechanisms might be the future directions, and the precise choice of the target population will assist us in seeking a more appropriate combination therapy for individuals to improve survival.

\section{Acknowledgments}

We would like to thank Shipeng $\mathrm{Xu}$, Qin Fang, Yuanyuan Fang, and Ruoyu Ji for their support.

Funding: This study is financially supported by the National Natural Science Foundation of China (8197103083, 81972484), and the National Key Research and Development Program of China (ZDZX2017ZL-01).

\section{Footnote}

Reporting Checklist: The authors have completed the Narrative Review reporting checklist. Available at http:// dx.doi.org/10.21037/tbcr-20-54

Conflicts of Interest: All authors have completed the ICMJE uniform disclosure form (available at http://dx.doi. org/10.21037/tbcr-20-54). YY serves as the unpaid editorial board member of Translational Breast Cancer Research. The other authors have no conflicts of interest to declare.

Etbical Statement: The authors are accountable for all aspects of the work in ensuring that questions related to the accuracy or integrity of any part of the work are appropriately investigated and resolved.

Open Access Statement: This is an Open Access article distributed in accordance with the Creative Commons Attribution-NonCommercial-NoDerivs 4.0 International License (CC BY-NC-ND 4.0), which permits the noncommercial replication and distribution of the article with the strict proviso that no changes or edits are made and the 
original work is properly cited (including links to both the formal publication through the relevant DOI and the license). See: https://creativecommons.org/licenses/by-nc-nd/4.0/.

\section{References}

1. Bray F, Ferlay J, Soerjomataram I, et al. Global cancer statistics 2018: GLOBOCAN estimates of incidence and mortality worldwide for 36 cancers in 185 countries. CA Cancer J Clin 2018;68:394-424.

2. Waks AG, Winer EP. Breast Cancer Treatment: A Review. JAMA 2019;321:288-300.

3. D'Souza A, Spicer D, Lu J. Overcoming endocrine resistance in metastatic hormone receptor-positive breast cancer. J Hematol Oncol 2018;11:80.

4. Spring LM, Wander SA, Andre F, et al. Cyclin-dependent kinase 4 and 6 inhibitors for hormone receptorpositive breast cancer: past, present, and future. Lancet 2020;395:817-27.

5. Weinberg RA. The retinoblastoma protein and cell cycle control. Cell 1995;81:323-30.

6. Narasimha AM, Kaulich M, Shapiro GS, et al. Cyclin $\mathrm{D}$ activates the $\mathrm{Rb}$ tumor suppressor by monophosphorylation. Elife 2014;3:e02872.

7. Sobhani N, D'Angelo A, Pittacolo M, et al. Updates on the CDK4/6 Inhibitory Strategy and Combinations in Breast Cancer. Cells 2019;8:321.

8. Millar EK, Dean JL, McNeil CM, et al. Cyclin D1b protein expression in breast cancer is independent of cyclin D1a and associated with poor disease outcome. Oncogene 2009;28:1812-20.

9. Bosco EE, Knudsen ES. RB in breast cancer: at the crossroads of tumorigenesis and treatment. Cell Cycle 2007;6:667-71.

10. Yu Q, Geng Y, Sicinski P. Specific protection against breast cancers by cyclin D1 ablation. Nature 2001;411:1017-21.

11. Yu Q, Sicinska E, Geng Y, et al. Requirement for CDK4 kinase function in breast cancer. Cancer Cell 2006;9:23-32.

12. Arnold A, Papanikolaou A. Cyclin D1 in breast cancer pathogenesis. J Clin Oncol 2005;23:4215-24.

13. Finn RS, Dering J, Conklin D, et al. PD 0332991, a selective cyclin D kinase 4/6 inhibitor, preferentially inhibits proliferation of luminal estrogen receptor-positive human breast cancer cell lines in vitro. Breast Cancer Res 2009;11:R77.

14. Finn RS, Martin M, Rugo HS, et al. Palbociclib and Letrozole in Advanced Breast Cancer. New Engl J Med 2016;375:1925-36.
15. Turner NC, Finn RS, Martin M, et al. Clinical considerations of the role of palbociclib in the management of advanced breast cancer patients with and without visceral metastases. Ann Oncol 2018;29:669-80.

16. Hortobagyi GN, Stemmer SM, Burris HA, et al. Ribociclib as First-Line Therapy for HR-Positive, Advanced Breast Cancer. N Engl J Med 2016;375:1738-48.

17. Goetz MP, Toi M, Campone M, et al. MONARCH 3: Abemaciclib As Initial Therapy for Advanced Breast Cancer. J Clin Oncol 2017;35:3638-46.

18. Youlden DR, Cramb SM, Yip CH, et al. Incidence and mortality of female breast cancer in the Asia-Pacific region. Cancer Biol Med 2014;11:101-15.

19. El Saghir NS, Khalil MK, Eid T, et al. Trends in epidemiology and management of breast cancer in developing Arab countries: a literature and registry analysis. Int J Surg 2007;5:225-33.

20. Rodríguez-Cuevas S, Macias CG, Franceschi D, et al. Breast carcinoma presents a decade earlier in Mexican women than in women in the United States or European countries. Cancer 2001;91:863-8.

21. DeSantis CE, Ma J, Goding Sauer A, et al. Breast cancer statistics, 2017, racial disparity in mortality by state. CA Cancer J Clin 2017;67:439-48.

22. Tripathy D, Im SA, Colleoni M, et al. Ribociclib plus endocrine therapy for premenopausal women with hormone-receptor-positive, advanced breast cancer (MONALEESA-7): a randomised phase 3 trial. Lancet Oncol 2018;19:904-15.

23. Im SA, Lu YS, Bardia A, et al. Overall Survival with Ribociclib plus Endocrine Therapy in Breast Cancer. N Engl J Med 2019;381:307-16.

24. Park YH, Kim TY, Kim GM, et al. Palbociclib plus exemestane with gonadotropin-releasing hormone agonist versus capecitabine in premenopausal women with hormone receptor-positive, HER2-negative metastatic breast cancer (KCSG-BR15-10): a multicentre, open-label, randomised, phase 2 trial. Lancet Oncol 2019;20:1750-9.

25. Park $\mathrm{YH}$, editor A randomized phase II study of palbociclib plus exemestane with GNRH agonist versus capecitabine in premenopausal women with hormone receptor-positive metastatic breast cancer (KCSG-BR 15-10, NCT02592746) 2019; ASCO Annual Meeting: American Society of Clinical Oncology.

26. Martin M, Zielinski C, Ruiz-Borrego M, et al. Results from PEARL study (GEICAM/2013-02_CECOG/BC.1.3.006): A phase 3 trial of Palbociclib (PAL) in combination with endocrine therapy (ET) versus Capecitabine (CAPE) 
in hormonal receptor (HR)-positive/human epidermal growth factor receptor (HER) 2-negative metastatic breast cancer (MBC) patients (pts) whose disease progressed on aromatase inhibitors (AIs). Cancer Res 2020;80:4.

27. Cristofanilli $M$, Turner NC, Bondarenko I, et al. Fulvestrant plus palbociclib versus fulvestrant plus placebo for treatment of hormone-receptor-positive, HER2negative metastatic breast cancer that progressed on previous endocrine therapy (PALOMA-3): final analysis of the multicentre, double-blind, phase 3 randomised controlled trial. Lancet Oncol 2016;17:425-39.

28. Turner NC, Slamon DJ, Ro J, et al. Overall Survival with Palbociclib and Fulvestrant in Advanced Breast Cancer. N Engl J Med 2018;379:1926-36.

29. Sledge GW Jr, Toi M, Neven P, et al. MONARCH 2: Abemaciclib in Combination With Fulvestrant in Women With HR+/HER2- Advanced Breast Cancer Who Had Progressed While Receiving Endocrine Therapy. J Clin Oncol 2017;35:2875-84.

30. Sledge GW Jr, Toi M, Neven P, et al. The Effect of Abemaciclib Plus Fulvestrant on Overall Survival in Hormone Receptor-Positive, ERBB2-Negative Breast Cancer That Progressed on Endocrine TherapyMONARCH 2: A Randomized Clinical Trial. JAMA Oncol 2020;6:116-24.

31. Slamon DJ, Neven P, Chia S, et al. Phase III Randomized Study of Ribociclib and Fulvestrant in Hormone ReceptorPositive, Human Epidermal Growth Factor Receptor 2-Negative Advanced Breast Cancer: MONALEESA-3. J Clin Oncol 2018;36:2465-72.

32. Slamon DJ, Neven P, Chia S, et al. Overall Survival with Ribociclib plus Fulvestrant in Advanced Breast Cancer. N Engl J Med 2020;382:514-24.

33. Llombart-Cussac A, editor PARSIFAL: A randomized, multicenter, open-label, phase II trial to evaluate palbociclib in combination with fulvestrant or letrozole in endocrine-sensitive patients with estrogen receptor (ER)[+]/HER2 [-] metastatic breast cancer2020; ASCO Virtual Scientific Program: American Society of Clinical Oncology.

34. Barton VN, D'Amato NC, Gordon MA, et al. Multiple molecular subtypes of triple-negative breast cancer critically rely on androgen receptor and respond to enzalutamide in vivo. Mol Cancer Ther 2015;14:769-78.

35. Gao S, Gao Y, He HH, et al. Androgen Receptor Tumor Suppressor Function Is Mediated by Recruitment of Retinoblastoma Protein. Cell Rep 2016;17:966-76.

36. Asghar US, Barr AR, Cutts R, et al. Single-Cell Dynamics
Determines Response to CDK4/6 Inhibition in TripleNegative Breast Cancer. Clin Cancer Res 2017;23:5561-72.

37. Liu CY, Lau KY, Hsu CC, et al. Combination of palbociclib with enzalutamide shows in vitro activity in $\mathrm{RB}$ proficient and androgen receptor positive triple negative breast cancer cells. PLoS One 2017;12:e189007.

38. Ji W, Shi Y, Wang X, et al. Combined Androgen receptor blockade overcomes the resistance of breast cancer cells to palbociclib. Int J Biol Sci 2019;15:522-32.

39. Witkiewicz AK, Cox D, Knudsen ES. CDK4/6 inhibition provides a potent adjunct to Her2-targeted therapies in preclinical breast cancer models. Genes Cancer 2014;5:261-72.

40. Goel S, Wang Q, Watt AC, et al. Overcoming Therapeutic Resistance in HER2-Positive Breast Cancers with CDK4/6 Inhibitors. Cancer Cell 2016;29:255-69.

41. Tolaney SM, Wardley AM, Zambelli S, et al. Abemaciclib plus trastuzumab with or without fulvestrant versus trastuzumab plus standard-of-care chemotherapy in women with hormone receptor-positive, HER2-positive advanced breast cancer (monarcHER): a randomised, open-label, phase 2 trial. Lancet Oncol 2020;21:763-75.

42. Gianni L, Bisagni G, Colleoni M, et al. Neoadjuvant treatment with trastuzumab and pertuzumab plus palbociclib and fulvestrant in HER2-positive, ER-positive breast cancer (NA-PHER2): an exploratory, open-label, phase 2 study. Lancet Oncol 2018;19:249-56.

43. Rimawi MF, Mayer IA, Forero A, et al. Multicenter phase II study of neoadjuvant lapatinib and trastuzumab with hormonal therapy and without chemotherapy in patients with human epidermal growth factor receptor 2-overexpressing breast cancer: TBCRC 006. J Clin Oncol 2013;31:1726-31.

44. Jiang Z, Hu X, Zhang Q, et al. MONARCHplus: A phase III trial of abemaciclib plus nonsteroidal aromatase inhibitor (NSAI) or fulvestrant (F) for women with HR+/HER2-advanced breast cancer (ABC). Ann Oncol 2019;30:863.

45. Hamilton E, Cortes J, Dieras V, et al. nextMONARCH 1: Phase 2 study of abemaciclib plus tamoxifen or abemaciclib alone in HR+, HER2- advanced breast cancer. Cancer Res 2019;79:2.

46. Cottu P, D'Hondt V, Dureau S, et al. Letrozole and palbociclib versus chemotherapy as neoadjuvant therapy of high-risk luminal breast cancer. Ann Oncol 2018;29:2334-40.

47. Bardia A, Hurvitz SA, DeMichele A, et al. Triplet therapy (continuous ribociclib, everolimus, exemestane) in $\mathrm{HR}+$ / 
HER2 - advanced breast cancer postprogression on a CDK4/6 inhibitor (TRINITI-1): Efficacy, safety, and biomarker results. J Clin Oncol 2019;37:1016.

48. Wander SA. editor. Phase Ib trial to evaluate safety and anti-tumor activity of the AKT inhibitor, ipatasertib, in combination with endocrine therapy and a CDK4/6 inhibitor for patients with hormone receptor positive $(\mathrm{HR}+) / H E R 2$ negative metastatic breast cancer (MBC) (TAKTIC) 2020; ASCO Virtual Scientific Program: American Society of Clinical Oncology.

49. Tan AR, Wright GS, Thummala AR, et al. Trilaciclib plus chemotherapy versus chemotherapy alone in patients with metastatic triple-negative breast cancer: a multicentre, randomised, open-label, phase 2 trial. Lancet Oncol 2019;20:1587-601.

50. Rugo HS. editor. A phase Ib study of abemaciclib in combination with pembrolizumab for patients with hormone receptor positive (HR+), human epidermal growth factor receptor 2 negative (HER2-) locally advanced or metastatic breast cancer (MBC) (NCT02779751): Interim results2020; ASCO Virtual Scientific Program: American Society of Clinical Oncology.

51. Cancer Genome Atlas Network. Comprehensive molecular portraits of human breast tumours. Nature 2012;490:61-70.

52. Vora SR, Juric D, Kim N, et al. CDK 4/6 inhibitors sensitize PIK3CA mutant breast cancer to PI3K inhibitors. Cancer Cell 2014;26:136-49.

53. Herrera-Abreu MT, Palafox M, Asghar U, et al. Early Adaptation and Acquired Resistance to CDK4/6 Inhibition in Estrogen Receptor-Positive Breast Cancer. Cancer Res 2016;76:2301-13.

54. Study of LEE011 with Fulvestrant and BYL719 or BKM120 in advanced breast cancer. ClinicalTrials website. Available online: https://www.clinicaltrials.gov/ct2/show/ NCT02088684? term=NCT02088684\&rank=1

55. Teo ZL, Versaci S, Dushyanthen S, et al. Combined $\mathrm{CDK} 4 / 6$ and PI3K $\alpha$ Inhibition Is Synergistic and Immunogenic in Triple-Negative Breast Cancer. Cancer Res 2017;77:6340-52.

56. Carpten JD, Faber AL, Horn C, et al. A transforming mutation in the pleckstrin homology domain of AKT1 in cancer. Nature 2007;448:439-44.

57. Stemke-Hale K, Gonzalez-Angulo AM, Lluch A, et al. An integrative genomic and proteomic analysis of PIK3CA, PTEN, and AKT mutations in breast cancer. Cancer Res 2008;68:6084-91.

58. Pérez-Tenorio G, Stål O. Activation of AKT/PKB in breast cancer predicts a worse outcome among endocrine treated patients. Br J Cancer 2002;86:540-5.

59. Tokunaga E, Kimura Y, Mashino K, et al. Activation of PI3K/Akt signaling and hormone resistance in breast cancer. Breast Cancer 2006;13:137-44.

60. Wander SA, Cohen O, Gong X, et al. The Genomic Landscape of Intrinsic and Acquired Resistance to Cyclin-Dependent Kinase 4/6 Inhibitors in Patients with Hormone Receptor-Positive Metastatic Breast Cancer. Cancer Discov 2020;10:1174-93.

61. Formisano L, Lu Y, Servetto A, et al. Aberrant FGFR signaling mediates resistance to CDK4/6 inhibitors in ER+ breast cancer. Nat Commun 2019;10:1373.

62. Formisano L, Stauffer KM, Young CD, et al. Association of FGFR1 with ER $\alpha$ Maintains Ligand-Independent ER Transcription and Mediates Resistance to Estrogen Deprivation in ER(+) Breast Cancer. Clin Cancer Res 2017;23:6138-50.

63. Mavaddat N, Barrowdale D, Andrulis IL, et al. Pathology of breast and ovarian cancers among BRCA1 and BRCA2 mutation carriers: results from the Consortium of Investigators of Modifiers of BRCA1/2 (CIMBA). Cancer Epidemiol Biomarkers Prev 2012;21:134-47.

64. Goodwin PJ, Phillips KA, West DW, et al. Breast cancer prognosis in BRCA1 and BRCA2 mutation carriers: an International Prospective Breast Cancer Family Registry population-based cohort study. J Clin Oncol 2012;30:19-26.

65. Phillips KA. Immunophenotypic and pathologic differences between BRCA1 and BRCA2 hereditary breast cancers. J Clin Oncol 2000;18:107S-112S.

66. Gorski JJ, Kennedy RD, Hosey AM, et al. The complex relationship between BRCA1 and ERalpha in hereditary breast cancer. Clin Cancer Res2009;15:1514-8.

67. Fan S, Wang J, Yuan R, et al. BRCA1 inhibition of estrogen receptor signaling in transfected cells. Science 1999;284:1354-6.

68. Hu Y, Ghosh S, Amleh A, et al. Modulation of aromatase expression by BRCA1: a possible link to tissue-specific tumor suppression. Oncogene 2005;24:8343-8.

69. Aprelikova ON, Fang BS, Meissner EG, et al. BRCA1associated growth arrest is RB-dependent. Proc Natl Acad Sci U S A 1999;96:11866-71.

70. Jirawatnotai S, Hu Y, Michowski W, et al. A function for cyclin D1 in DNA repair uncovered by protein interactome analyses in human cancers. Nature 2011;474:230-4.

71. Dean JL, McClendon AK, Knudsen ES. Modification of the DNA damage response by therapeutic CDK4/6 inhibition. J Biol Chem 2012;287:29075-87. 
72. Militello AM, Zielli T, Boggiani D, et al. Mechanism of Action and Clinical Efficacy of CDK4/6 Inhibitors in BRCA-Mutated, Estrogen Receptor-Positive Breast Cancers: Case Report and Literature Review. Front Oncol 2019;9:759.

73. Zimmer AS, Gillard M, Lipkowitz S, et al. Update on PARP Inhibitors in Breast Cancer. Curr Treat Options Oncol 2018;19:21.

74. Lord CJ, Tutt AN, Ashworth A. Synthetic lethality and cancer therapy: lessons learned from the development of PARP inhibitors. Annu Rev Med 2015;66:455-70.

75. Robson M, Im SA, Senkus E, et al. Olaparib for Metastatic Breast Cancer in Patients with a Germline BRCA Mutation. N Engl J Med 2017;377:523-33.

76. Litton JK, Rugo HS, Ettl J, et al. Talazoparib in Patients with Advanced Breast Cancer and a Germline BRCA Mutation. N Engl J Med 2018;379:753-63.

77. Roberts PJ, Bisi JE, Strum JC, et al. Multiple roles of cyclin-dependent kinase 4/6 inhibitors in cancer therapy. $\mathrm{J}$ Natl Cancer Inst 2012;104:476-87.

78. Johnson SM, Torrice CD, Bell JF, et al. Mitigation of hematologic radiation toxicity in mice through pharmacological quiescence induced by CDK4/6 inhibition. J Clin Invest 2010;120:2528-36.

79. Lyman GH. Chemotherapy dose intensity and quality cancer care. Oncology 2006;20:16-25.

80. Goel S, DeCristo MJ, Watt AC, et al. CDK4/6 inhibition triggers anti-tumour immunity. Nature 2017;548:471-5.

81. Deng J, Wang ES, Jenkins RW, et al. CDK4/6 Inhibition Augments Antitumor Immunity by Enhancing T-cell Activation. Cancer Discov 2018;8:216-33.

82. Zhang J, Bu X, Wang H, et al. Cyclin D-CDK4 kinase destabilizes PD-L1 via cullin 3-SPOP to control cancer immune surveillance. Nature 2018;553:91-5.

83. Fassl A, Brain C, Abu-Remaileh M, et al. Increased lysosomal biomass is responsible for the resistance of

doi: 10.21037/tbcr-20-54

Cite this article as: Yang $\mathrm{Y}, \mathrm{Zhu} \mathrm{S}, \mathrm{Fu} \mathrm{Z}$, Sun C, Yang F, Zeng T, Hua Y, Bao S, Gao X, Huang X, Li W, Yin Y. Cyclindependent kinase 4 and 6 inhibitors at the crossroads: the combinational therapeutic strategies in breast cancer-a narrative review. Transl Breast Cancer Res 2021;2:13. triple-negative breast cancers to CDK4/6 inhibition. Sci Adv 2020;6:eabb2210.

84. Witzel I, Oliveira-Ferrer L, Pantel K, et al. Breast cancer brain metastases: biology and new clinical perspectives. Breast Cancer Res 2016;18:8.

85. Lin NU, Bellon JR, Winer EP. CNS metastases in breast cancer. J Clin Oncol 2004;22:3608-17.

86. Ramakrishna N, Temin S, Chandarlapaty S, et al. Recommendations on Disease Management for Patients With Advanced Human Epidermal Growth Factor Receptor 2-Positive Breast Cancer and Brain Metastases: ASCO Clinical Practice Guideline Update. J Clin Oncol 2018;36:2804-7.

87. Raub TJ, Wishart GN, Kulanthaivel P, et al. Brain Exposure of Two Selective Dual CDK4 and CDK6 Inhibitors and the Antitumor Activity of CDK4 and CDK6 Inhibition in Combination with Temozolomide in an Intracranial Glioblastoma Xenograft. Drug Metab Dispos 2015;43:1360-71.

88. Tolaney SM, Sahebjam S, Le Rhun E, et al. A Phase II Study of Abemaciclib in Patients with Brain Metastases Secondary to Hormone Receptor-Positive Breast Cancer. Clin Cancer Res 2020;26:5310-9.

89. Whittaker S, Madani D, Joshi S, et al. Combination of palbociclib and radiotherapy for glioblastoma. Cell Death Discov 2017;3:17033.

90. Hashizume R, Zhang A, Mueller S, et al. Inhibition of DNA damage repair by the CDK4/6 inhibitor palbociclib delays irradiated intracranial atypical teratoid rhabdoid tumor and glioblastoma xenograft regrowth. Neuro Oncol 2016;18:1519-28.

91. Figura NB, Potluri TK, Mohammadi H, et al. CDK 4/6 inhibitors and stereotactic radiation in the management of hormone receptor positive breast cancer brain metastases. J Neurooncol 2019;144:583-9. 